\title{
Moho and Philippine Sea plate structure beneath central Honshu Island, Japan, from teleseismic receiver functions
}

\author{
Kazuo Yoshimoto ${ }^{1}$, Hiroatsu Fujisawa ${ }^{2}$, Tomomi Okada ${ }^{2}$, Norihito Umino ${ }^{2}$, Akira Hasegawa ${ }^{2}$, Kazushige Obara $^{3}$, \\ Katsuhiko Shiomi ${ }^{3}$, Hiroaki Tsukahara ${ }^{4}$, Shigeru Okamoto ${ }^{5}$, Taku Kawanaka ${ }^{5}$, \\ Hiroshi Sato ${ }^{6}$, Takeshi Nishimura ${ }^{2}$, Haruo Sato ${ }^{2}$, and Masakazu Ohtake ${ }^{2}$ \\ ${ }^{1}$ Graduate School of Integrated Science, Yokohama City University, 22-2 Seto, Kanazawa, Yokohama 236-0027, Japan \\ ${ }^{2}$ Graduate School of Science, Tohoku University, Aramaki, Aoba, Sendai, Miyagi 980-8578, Japan \\ ${ }^{3}$ National Research Institute for Earth Science and Disaster Prevention, 3-1 Tennodai, Tsukuba, Ibaraki 305-0006, Japan \\ ${ }^{4}$ Faculty of Science, Shinshu University, 3-1-1 Asahi, Matsumoto, Nagano 390-8621, Japan \\ ${ }^{5}$ JGI inc., 1-5-21 Otsuka, Bunkyo, Tokyo 112-0012, Japan \\ ${ }^{6}$ Earthquake Research Institute, University of Tokyo,1-1-1 Yayoi, Bunkyo, Tokyo 113-0032, Japan
}

(Received May 30, 2004; Revised September 3, 2004; Accepted September 27, 2004)

\begin{abstract}
We used teleseismic $P$ waves recorded by the J-array, the Hi-net and a temporal local seismic network to investigate the three-dimensional topography of the Moho and the Philippine Sea plate beneath central Honshu Island, Japan. An image of the subsurface discontinuities beneath the region, derived from receiver function analysis, depicts the Philippine Sea plate dipping toward the north with complex local curvatures. The Moho is clearly detected in the northern part of the area studied, and its depth increases to the center of the island. Receiver functions from the stations adjacent to the Itoigawa-Shizuoka tectonic line indicate the step-like topography of the Moho directly beneath this tectonic line.
\end{abstract}

Key words: Moho, Philippine Sea plate, Itoigawa-Shizuoka tectonic line, median tectonic line, receiver function.

\section{Introduction}

In central Honshu Island, Japan, the Itoigawa-Shizuoka tectonic line (ISTL), which forms the western margin of the Fossa Magna, runs from the north to the south (Fig. 1). The geological deformation process of the shallow structure of the ISTL and the median tectonic line (MTL), which intersects the ISTL in this region, has been studied by many researchers (e.g., Ogawa et al., 2002; Sagiya et al., 2002; Niitsuma et al., 2003). Another large-scale tectonics in this region is the subduction of oceanic plates. The Philippine Sea plate subducts toward the northwest from the Suruga trough and the Sagami trough, and the Pacific plate subducts from the Japan trench, with its upper plane located at a depth of about $200 \mathrm{~km}$ (Ishida, 1992).

There are few studies on the structure of the lower crust and uppermost mantle beneath central Honshu. Reports on the regional Moho topography from seismic refraction surveys are limited to several profiles: e.g., the Atsumi-Noto profile (Aoki et al., 1972; Iidaka et al., 2003). The seismic data of the ISTL obtained by reflection and refraction surveys are restricted to near the upper crust (e.g., Ikami et al., 1986). The structure of the subducting Philippine Sea plate has been extensively investigated using the spatial distribution of hypocenters at the plate boundary (e.g., Ishida, 1992). These studies have revealed the fine structure of the upper plane of the Philippine Sea plate at depths of less than

Copy right(c) The Society of Geomagnetism and Earth, Planetary and Space Sciences (SGEPSS); The Seismological Society of Japan; The Volcanological Society of Japan; The Geodetic Society of Japan; The Japanese Society for Planetary Sciences; TERRAPUB about $50 \mathrm{~km}$. However, in these previous studies, there was difficulty in depicting deeper seismicity. The seismic traveltime tomography is an alternative technique for investigating the geometry of aseismic slabs. The use of teleseismic data effectively extends the extrapolation depths. In spite of this advantage, it is difficult to image a discontinuous structure where seismic velocities change abruptly.

This study applies a receiver function technique to find the conversion phases from subsurface discontinuities and to depict the regional topography of the Moho and the Philippine Sea plate beneath central Honshu Island, Japan.

\section{Data}

This study analyzes teleseismic waveforms recorded by the J-array, the Hi-net, and a temporary seismic network deployed for this study. The average spatial separation of stations was about $20 \mathrm{~km}$.

From the J-array, we selected three-component seismic stations that operated for more than two months between November 1996 and June 2003. In addition, because of the excellent data quality, several broadband seismic stations were exceptionally selected, even though they had a short operation time. The selected 105 stations consisted of 78 short-period stations, 4 broadband stations, and 23 multi-instrument stations. The resolution of A/D conversion ranged from 10 to 24 bits, and $80 \%$ of the recording systems had a resolution of higher than 20 bits.

We selected 173 stations from the Hi-net. Teleseismic waveforms were collected over 34 months between October 2000 and July 2003, except for 96 stations, which have been operating since April 2003. At all stations, seismic signals 


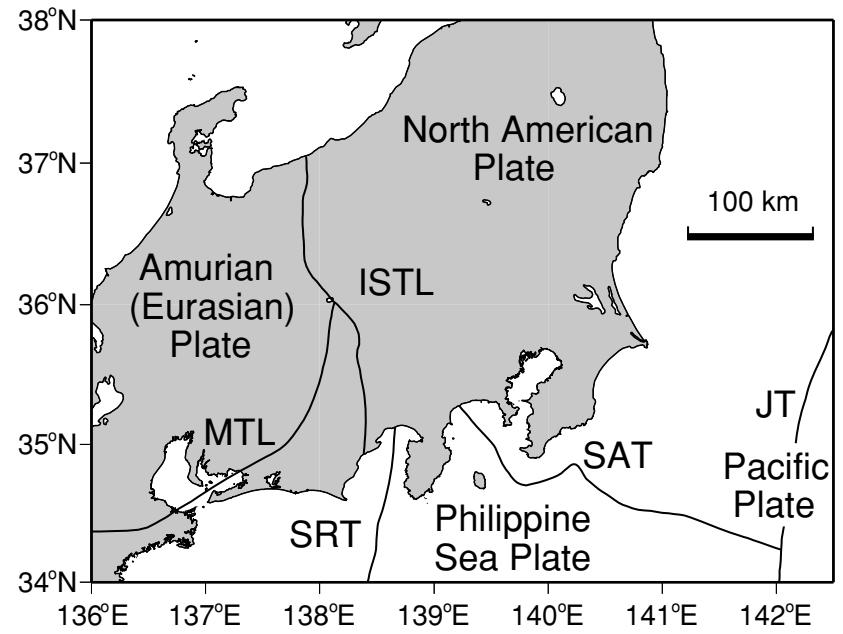

Fig. 1. Tectonic setting of central Honshu, Japan: ISTL, Itoigawa-Shizuoka tectonic line; JT, Japan trench; MTL, median tectonic line; SAT, Sagami trough; SRT, Suruga trough.

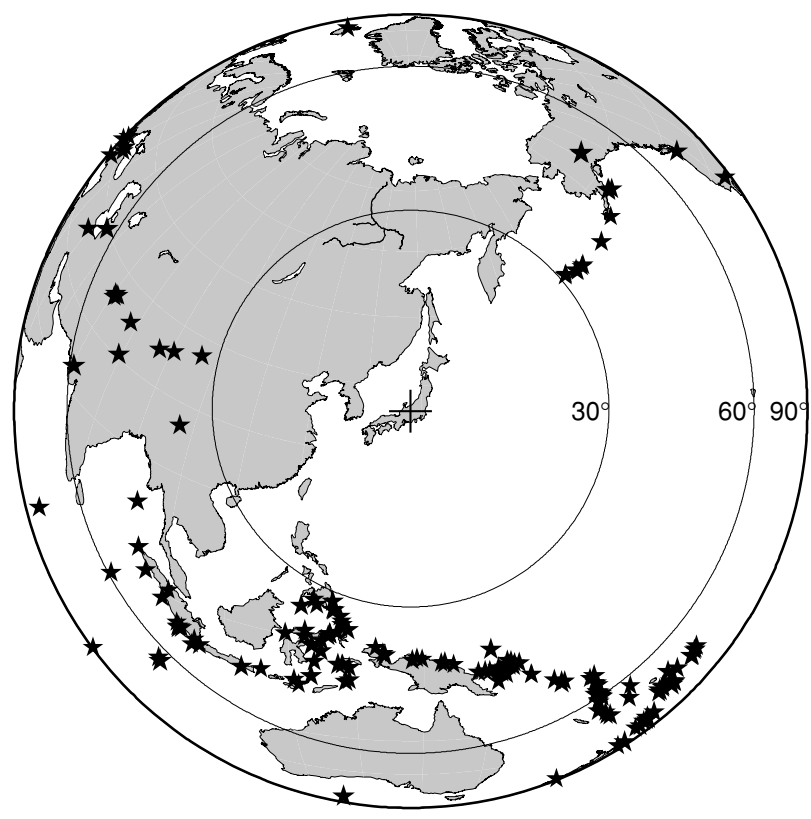

Fig. 2. Azimuthal equidistant projection showing the distribution of earthquakes (solid stars) used in this study. The circles indicate epicentral distances of $30^{\circ}, 60^{\circ}$, and $90^{\circ}$ from the center of the area studied.

from a three-component velocity seismometer with natural frequency of $1 \mathrm{~Hz}$ were sampled with 27-bit resolution at 100 samples/s.

A temporary seismic observation was carried out around the northern and central part of the ISTL from May 2002 to January 2003 (Yoshimoto et al., 2002). Eleven stations were deployed to fill the spatial gaps of the J-array and Hi-net. The output signals from the Mark Products L-4 seismometers were sampled with 16- or 24-bit resolution using 100 samples/s.

In the receiver function analysis, we used 257 stations from these seismic networks and 166 earthquakes that range in epicentral distance from $30^{\circ}$ to $90^{\circ}$, and in magnitude from 6.0 to 7.0 (Fig. 2).

\section{Receiver Function Analysis}

To investigate the subsurface structures down to the Philippine Sea plate, teleseismic waveforms are windowed from $5 \mathrm{~s}$ before to $30 \mathrm{~s}$ after the $P$ wave arrival. The IASP91 reference model is used to calculate the arrival time (Kennett and Engdahl, 1991). The hypocentral parameters are taken from the Preliminary Determination of Epicenters (PDE list) of the U. S. Geological Survey. Most of the back-azimuths of earthquakes lie between $140^{\circ}$ and $210^{\circ}$.
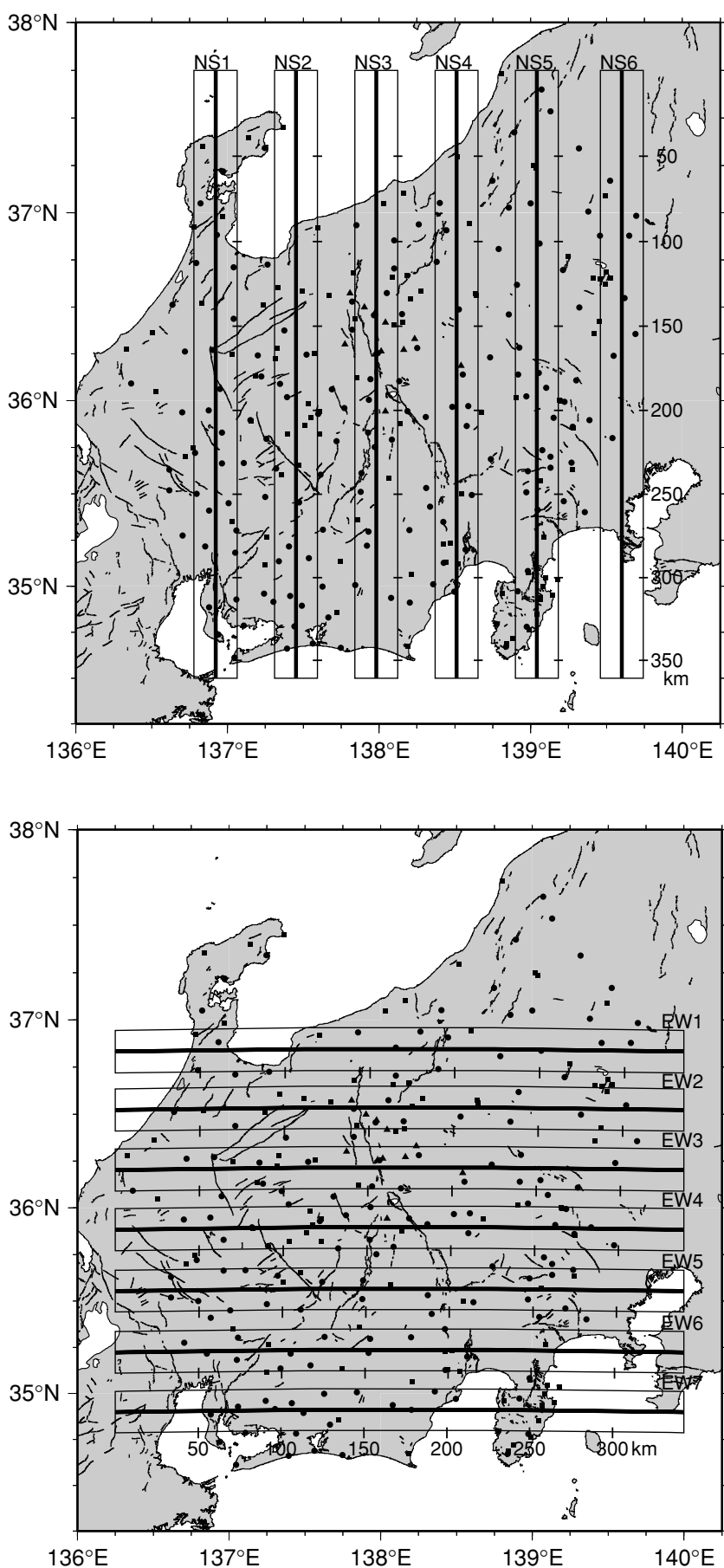

Fig. 3. A map showing locations of seismic stations and profile lines used in this study. J-array stations (squares), Hi-net stations (circles), and temporary network stations (triangles). RF depth image of each profile is calculated by using the receiver functions in the rectangle area. The solid lines denote active faults. 

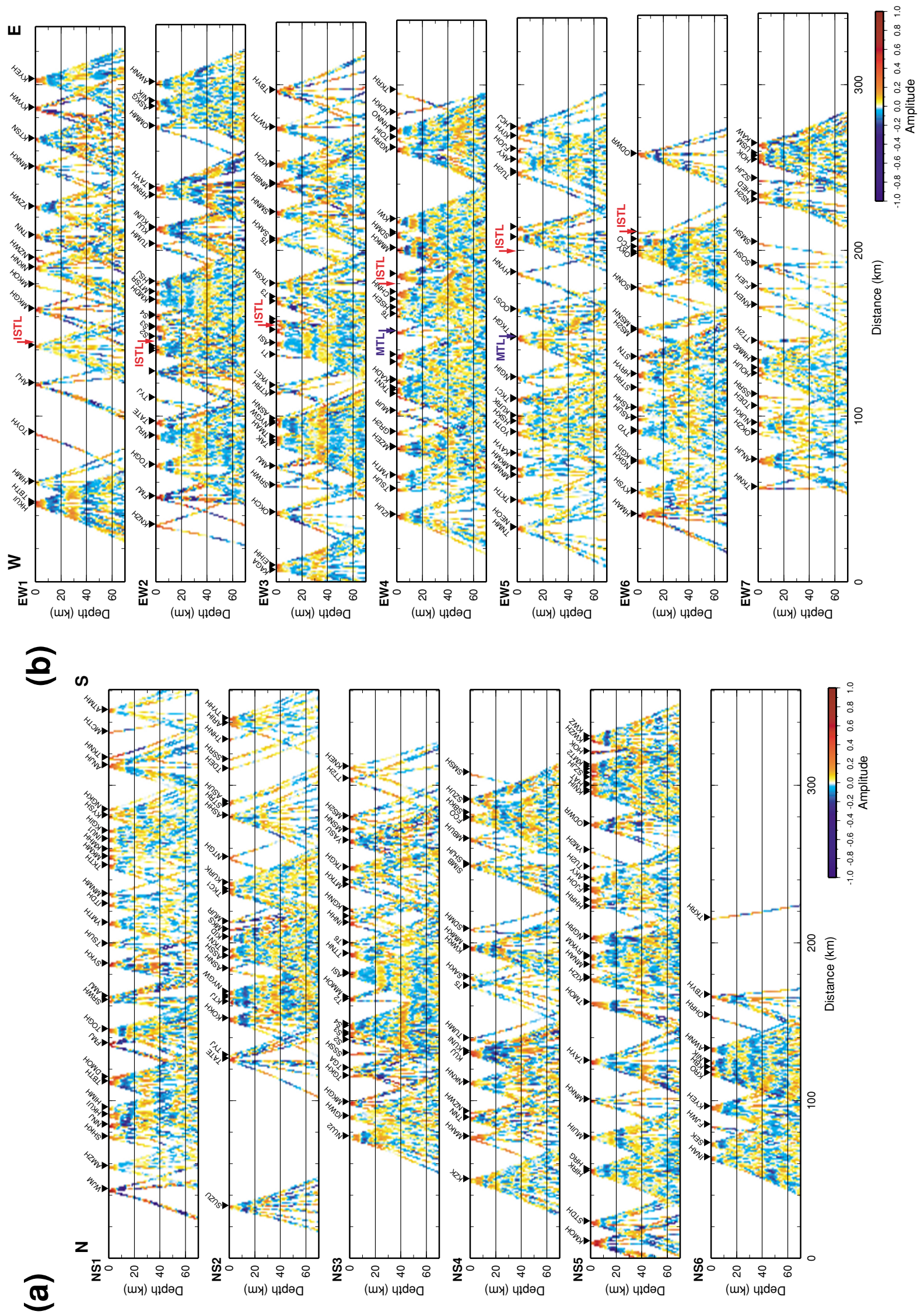

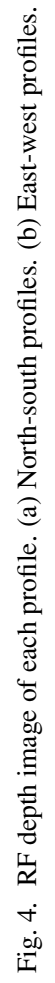



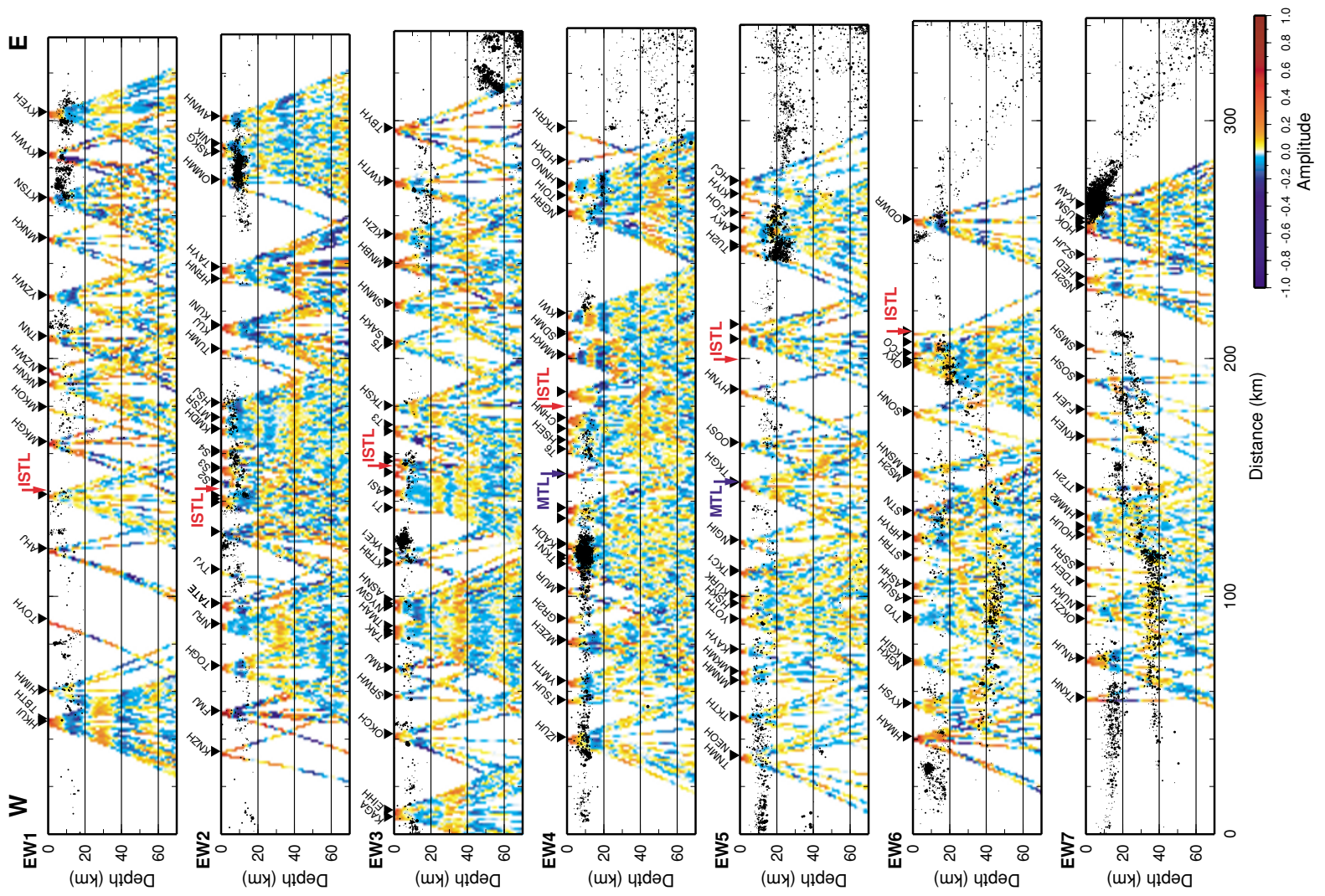

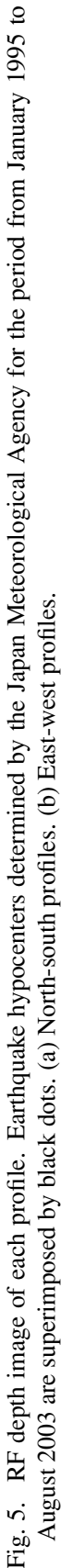
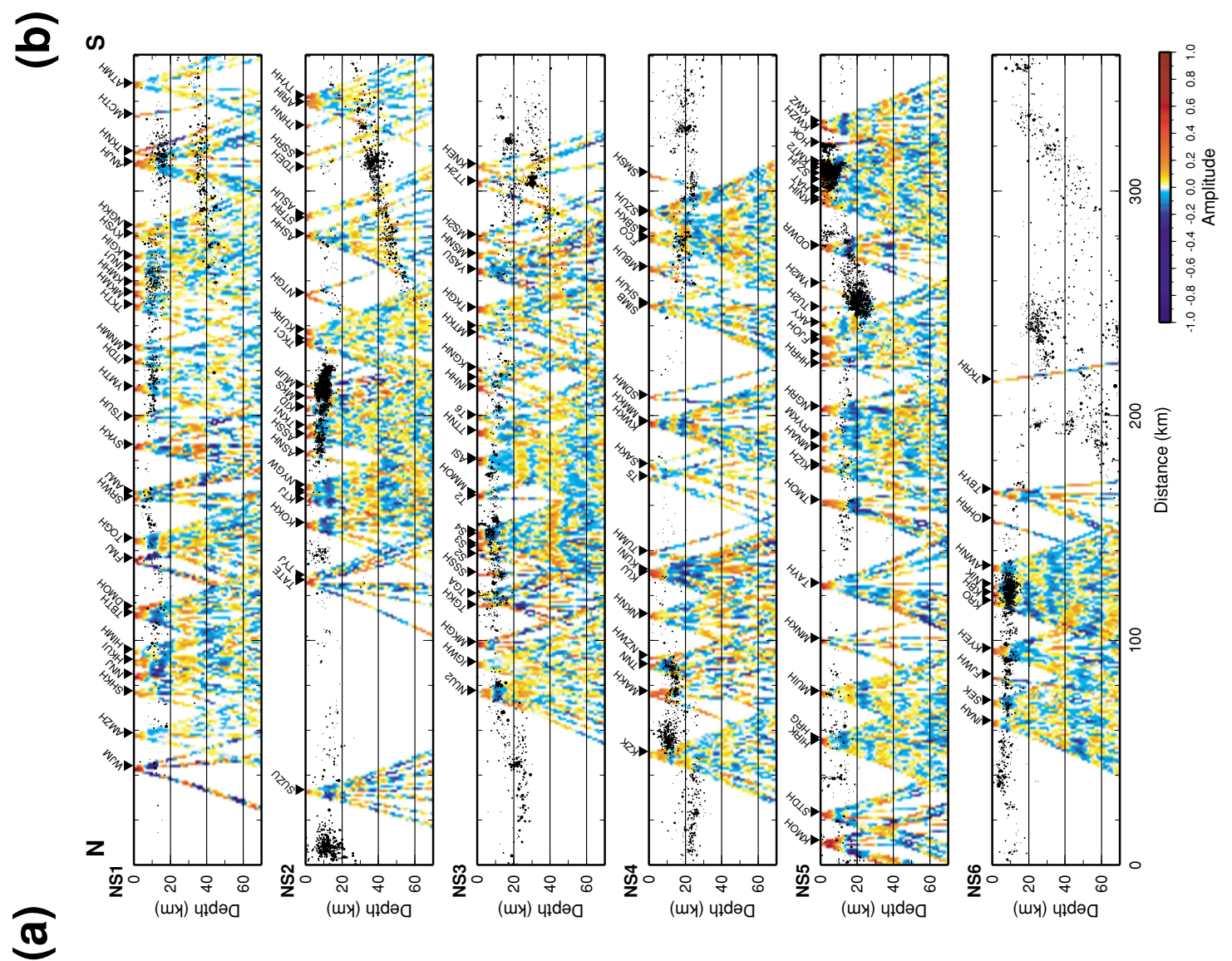

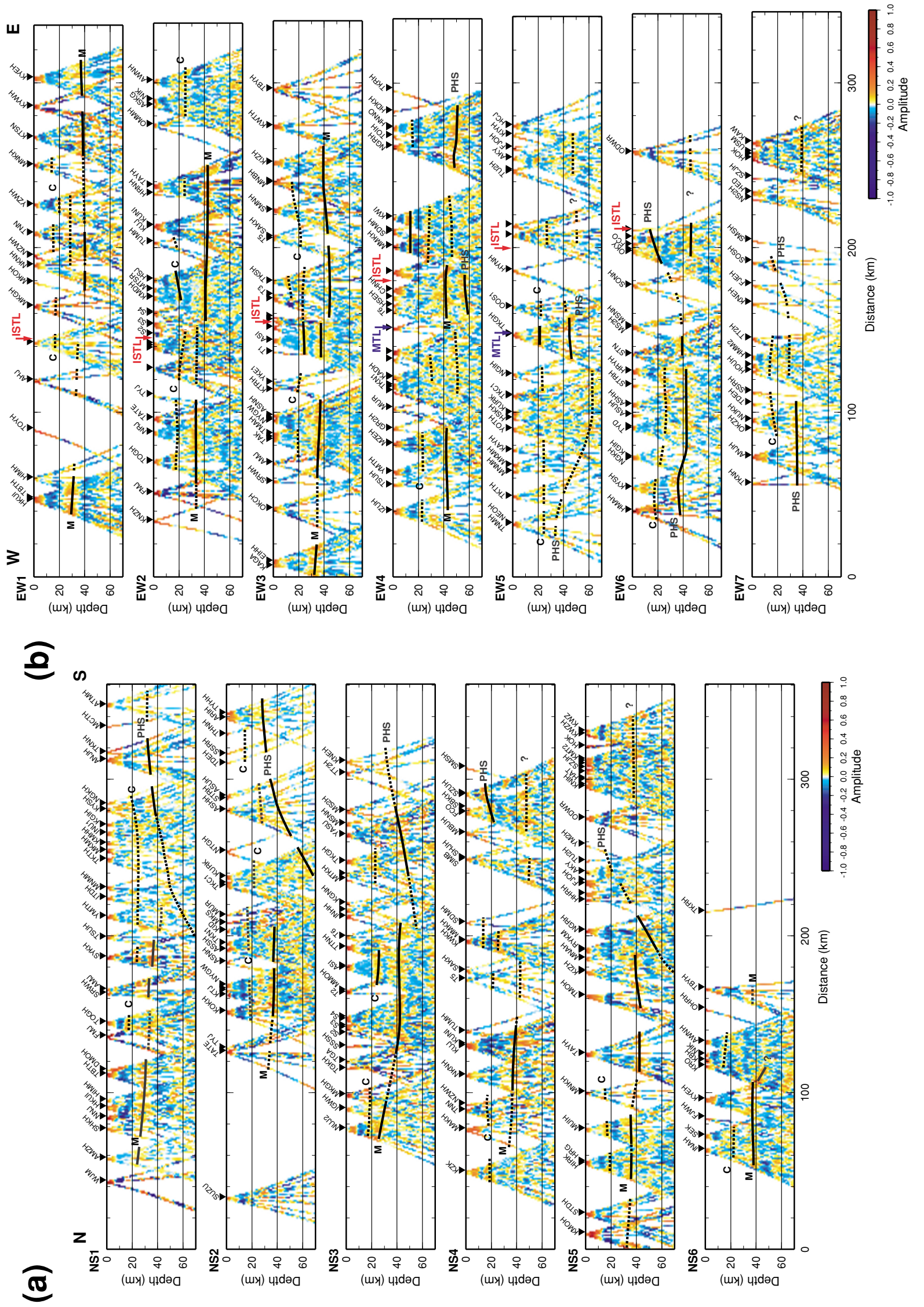

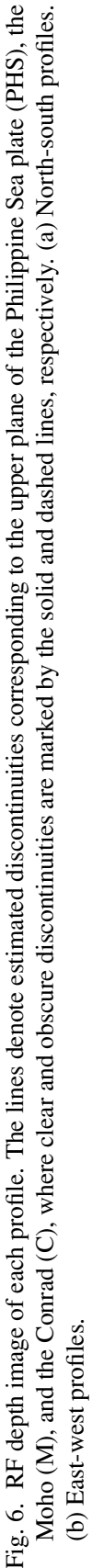


Seismograms with clear $P P$ arrivals are discarded because of their different ray parameters with respect to direct $P$ waves. Receiver functions are calculated from the vertical and radial component seismograms. The deconvolution is conducted using the spectral division technique with a water level parameter of 0.001 . The cosine taper of $2 \mathrm{~s}$ in length is used in the calculation. To remove the high-frequency noise and stabilize deconvolution, we apply a Gaussian low-pass filter with $-3 \mathrm{~dB}$ cutoff at $0.56 \mathrm{~Hz}$ ( $\alpha=3$ in the notation of Owens et al., 1984).

After visual inspection to remove unstable receiver functions, on which large ripples preceding the $P$ arrival were found, we obtained 4179 receiver functions through a series of screening processes. In this analysis, assuming the single $P s$ conversion at velocity discontinuities, we transformed the time domain receiver functions into the space domain based on the migration technique (Gurrola et al., 1994). We adopted the IASP91 velocity model for this calculation. To obtain a stable three-dimensional image beneath the target area, we stacked the space-domain receiver functions within a square block of $1 \mathrm{~km}$-width and took the average value (hereafter called the RF depth image).

\section{Results and Discussion}

We set 6 north-south profile lines (NS1-NS6) and 7 eastwest profile lines (EW1-EW7) to evaluate the regional variation in subsurface discontinuities (Fig. 3). Figure 4 shows the vertical projections of RF depth images in the area within a $12.5-\mathrm{km}$ distance from each profile line. The color red corresponds to the positive receiver function amplitudes, which are related to an increase in velocity with depth, and the color blue corresponds to negative amplitudes.

On the north-south profiles, the subduction of the Philippine Sea plate from the south-edge is anticipated. These profiles show strong conversion phases with positive polarity dipping to the north. These phases, which are marked by the color red, show good spatial correlation with the hypocenters (Fig. 5). The spatial continuity of these phases is especially clear on NS1 and NS2. On both profiles, this continuity can be traced down to a depth of $70 \mathrm{~km}$. Phase continuities can also be found at depths of 30-50, 10-20, and 40-60 km on NS3, NS4, and NS5, respectively.

On the east-west profiles, the corresponding phases are found on the southward profiles. On EW4, a distinct subhorizontal continuity appears beneath the stations between $\mathrm{NGRH}$ and HDKH at depths of about $50 \mathrm{~km}$. In the western part of the region studied, saucer-shaped continuities can be seen at depths of 30-60 and 30-40 km on EW5 and EW6, respectively. The spatial correlation between the phase continuity and hypocenters is especially clear on EW6.

From the observed characteristics summarized above, these phases with positive polarity in the RF depth image can be interpreted as conversion phases from the subducting Philippine Sea plate. It is reported through previous receiver function studies on the Philippine Sea plate (e.g., Shiomi et al., 2004) that the Ps conversion occurs at the oceanic Moho on the subducting slab.

The phases with positive polarity observed beneath the inland area at a depth of about $30-40 \mathrm{~km}$ can be interpreted

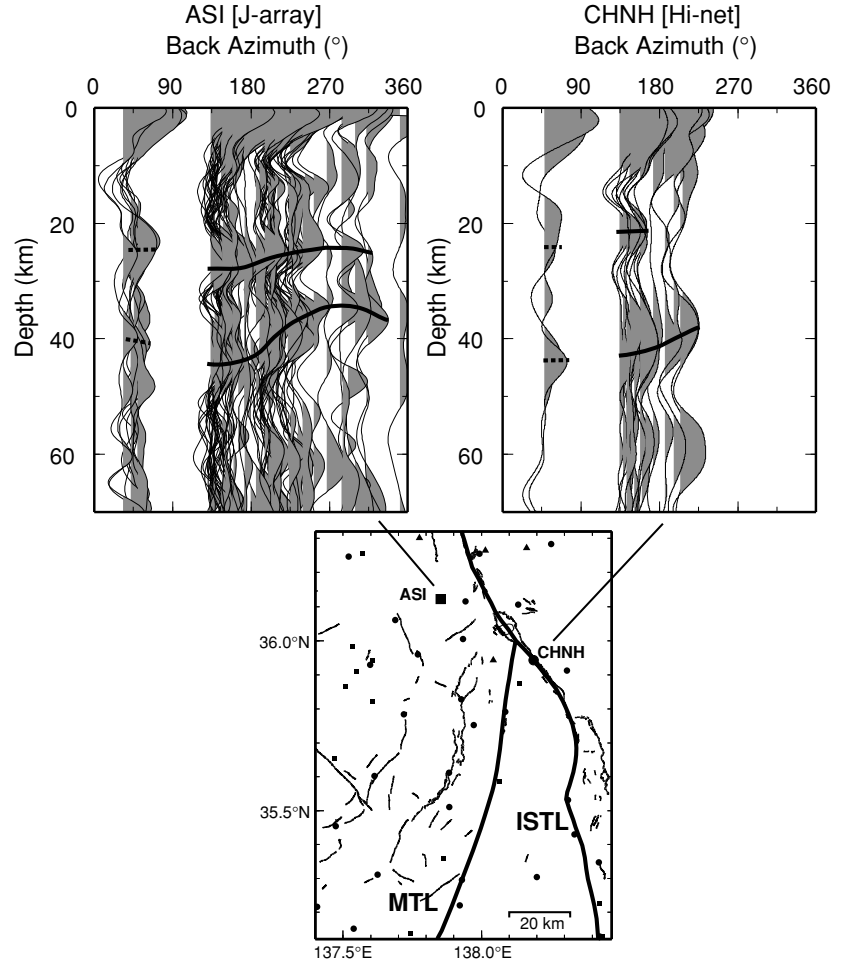

Fig. 7. Depth converted receiver functions versus back azimuth. Positive amplitude arrivals are shaded. Coherent and semi-coherent phases are marked by the solid and dashed lines, respectively.

as the conversion phases from the Moho. The subhorizontal continuity is clear in the middle and northern part of the area studied. This continuity has a regional trend dipping to the south on all north-south profiles. On the east-west profiles, the depth of the corresponding phases increases from the west to the east. The regional variation in the Moho topography is roughly consistent with that reported by Zhao et al. (1992). However, although the converted phases considered to be generated at the Conrad are clear, their continuities are not very evident; this is due to the insufficient coverage of incident rays at shallow depths.

Figure 6 shows the estimated regional depth variation in the upper plane of the Philippine Sea plate, the Moho, and the Conrad, where the solid and dashed lines correspond to the clear and obscure continuity of the converted phases, respectively. These lines are drawn by connecting the center of the color red on the vertical profiles as smoothly as possible. The dashed lines refer to the hypocentral distribution of the upper plane of the Philippine Sea plate. Due to the uncertainty arising from the reference velocity model (IASP91), we have restricted our attention to only the dominant horizontal structural variations, and we do not discuss their absolute depths with a scale finer than $5 \mathrm{~km}$.

This study successfully traces the upper plane of the subducting Philippine Sea plate to a latitude of about $36^{\circ} \mathrm{N}$. The estimated geometry of this plane in the Kanto region $\left(>139^{\circ} \mathrm{E}\right)$ is consistent with that obtained by Ishida (1992) based on regional seismicity analysis. On the other hand, the receiver functions calculated for the Tokai region $\left(<139^{\circ} \mathrm{E}\right)$ depict the upper plane of the subducting slab down to a depth of $70 \mathrm{~km}$, where it is difficult to apply con- 
ventional seismicity analysis (see low seismicity on NS1 and NS2). The aseismic Philippine sea plate depicted on the NS3 cross-section is coincident with that reported by Sekiguchi (2001) from seismic tomography analysis. The irregularity of the converted phases observed at depths of about 50-60 km beneath NGIH on EW5 may correspond to the large curvature of the Philippine Sea plate as suggested by Yamazaki et al. (1989). The clear phase continuity found at depths of about $40 \mathrm{~km}$ beneath the Izu Peninsula and the surrounding region should be closely investigated in future analysis to obtain a geological interpretation.

On the profiles from EW2 to EW4, the depth of the Moho is discontinuous directly beneath the ISTL. A downward offset of about $5 \mathrm{~km}$ is found across the ISTL from the west to the east. To verify this discontinuity by minimizing the effects of horizontal velocity perturbation in the shallow crust, we investigated the back azimuthal variation in receiver functions for 2 stations adjacent to the ISTL. This analysis does not reduce the travel time fluctuation caused by local heterogeneity in the lower crust. However, this fluctuation is expected to be much smaller than that observed in the receiver functions $(>0.5 \mathrm{~s})$. Figure 7 plots the depth-converted receiver functions plotted versus back azimuth, where the coherent and semi-coherent phases are marked by the solid and dashed lines, respectively. At station ASI and CHNH, the conversion depth of the Moho phase increases to the east of the ISTL. These results are consistent with those obtained in the previous array analysis (Fig. 6) and strongly indicate a sudden increase in Moho depth right beneath the ISTL.

Acknowledgments. The authors are indebted to the University of Tokyo, Nagoya University, Kyoto University, and the Japan Meteorological Agency for providing the J-array data. We acknowledge the National Research Institute for Earth Science and Disaster Prevention for providing the Hi-net data. We appreciate the suggestive reviews of Stephen C. Bannister and an anonymous referee. We also thank Charles J. Ammon for the computer code used in our analysis. This study is conducted as a part of the "Comprehensive Research on Slip and Flow Processes in and below the Seismogenic Region" supported by the Special Coordination Funds of the Ministry of Education, Culture, Sports, Science and Technology.

\section{References}

Aoki, H., T. Tada, Y. Sasaki, T. Ooida, I. Muramatsu, H. Shimamura, and
I. Furuya, Crustal structure in the profile across Central Japan as derived from explosion seismic observations, J. Phys. Earth, 20, 197-223, 1972. Gurrola, H., J. B. Minster, and T. Owens, The use of velocity spectrum for stacking receiver functions and imaging upper mantle discontinuities, Geophys. J. Int., 117, 427-440, 1994.

Iidaka, T., T. Iwasaki, T. Takeda, T. Moriya, I. Kumakawa, E. Kurashimo, T. Kawamura, F. Yamazaki, K. Koike, and G. Aoki, Configuration of subducting Philippine Sea plate and crustal structure in the central Japan region, Geophys. Res. Lett., 30, doi:10.1029/2002GL016517, 2003.

Ikami, A., T. Yoshii, S. Kubota, Y. Sakai, A. Hasemi, T. Moriya, H. Miyamachi, R. S. Matsu'ura, and K. Wada, A seismic-refraction profile in and around Nagano Prefecture, central Japan, J. Phys. Earth, 34, 457474, 1986.

Ishida, M., Geometry and relative motion of the Philippine Sea Plate and Pacific Plate beneath the Kanto-Tokai district, Japan, J. Geophys. Res., 97, 489-513, 1992.

Kennett, B. L. N. and E. R. Engdahl, Traveltimes for global earthquake location and phase identification, Geophys. J. Int., 105, 429-465, 1991.

Niitsuma, S., N. Niitsuma, and K. Saito, Evolution of the Komiji Syncline in the North Fossa Magna, central Japan: Paleomagnetic and K-Ar age insights, The Island Arc, 12, 310-323, 2003.

Ogawa, Y., S. Takakura, and Y. Honkura, Resistivity structure across Itoigawa-Shizuoka tectonic line and its implications for concentrated deformation, Earth Planets Space, 54, 1115-1120, 2002.

Owens, T. J., G. Zandt, and S. R. Taylor, Seismic evidence for an ancient rift beneath the Cumberland Plateau, Tennessee: A detailed analysis of broadband teleseismic P wave-forms, J. Geophys. Res., 89, 7783-7795, 1984.

Sagiya, T., T. Nishimura, Y. Iio, and T. Tada, Crustal deformation around the northern and central Itoigawa-Shizuoka Tectonic Line, Earth Planets Space, 54, 1059-1063, 2002.

Sekiguchi, S., A new configuration and an aseismic slab of the descending Philippine Sea plate revealed by seismic tomography, Tectonophysics, 341, 19-32, 2001.

Shiomi, K., H. Sato, K. Obara, and M. Ohtake, Configuration of subducting Philippine Sea plate beneath southwest Japan revealed from receiver function analysis based on the multivariate autoregressive model, $J$. Geophys. Res., 109, B04308, doi:10.1029/2003JB002774, 2004.

Yamazaki, F., T. Ooida, and H. Aoki, Subduction of Philippine Sea Plate beneath the Tokai area, central Japan, J. Earth Sci. Nagoya Univ., 36, 15-26, 1989.

Yoshimoto, K., H. Fujisawa, T. Okada, N. Umino, A. Hasegawa, K. Obara, H. Tsukahara, S. Okamoto, T. Kawanaka, H. Sato, H. Sato, and M. Ohtake, Seismic observation for investigating deep crustal structure around the Itoigawa-Shizuoka tectonic line, Program and Abstracts of the SSJ Fall Meeting 2002, C22, 2002 (in Japanese).

Zhao, D., S. Horiuchi, and A. Hasegawa, Seismic velocity structure of the crust beneath the Japan Islands, Tectonophysics, 212, 289-301, 1992.

K. Yoshimoto (e-mail: k_yoshi@yokohama-cu.ac.jp), H. Fujisawa, T. Okada, N. Umino, A. Hasegawa, K. Obara, K. Shiomi, H. Tsukahara, S. Okamoto, T. Kawanaka, H. Sato, T. Nishimura, H. Sato, and M. Ohtake 